\title{
Uma leitura das relações entre língua e sociedade em Émile Benveniste a partir da noção de gesto
}

Silvana Silva*

\section{Resumo}

O objetivo do presente artigo é empreender uma leitura da noção de sociedade em Benveniste, a partir da articulação entre língua/indivíduo/sociedade. Para realizar esse propósito, faremos uma leitura transversal entre os artigos "A semiologia da língua", de Problemas de Linguística Geral I, e "Philos", do livro Estatutos sociais, da obra Vocabulário das Instituições Indo-europeias I, de Émile Benveniste. Uma das primeiras observações é que a noção de gesto é o elo que une língua e sociedade. Em função dessa constatação, decidimos investigar mais detidamente a noção de gesto em Benveniste. A partir do estudo do texto "A forma e o sentido na linguagem", de Benveniste, foi possível começar a compreender o lugar do gesto na língua e sua relação com o par língua/discurso.

Palavras-chave: Sociedade. Gesto em perspectiva enunciativa. Émile Benveniste.

\section{Introdução}

Sabe-se que muitos dos estudos enunciativos, tal como desenvolvidos no Brasil, centralizam sua atenção nos Problemas de Linguística Geral I e II, de Benveniste, e, em especial, na seção "O homem na língua”. Dessa leitura advém a chamada Linguística da Enunciação, sintetizada em Flores et al. (2009), a qual estabelece um quadro preciso com categorias bem demarcadas de análise enunciativa. No entanto, algumas pesquisas na França, tais como a de Ono (2007), apresentam um estudo que integra as perspectivas sobre o objeto enunciativo a outras obras do autor, tal como o Vocabulário das Instituições Indo-europeias, permitindo-nos ter uma visão

\footnotetext{
Doutora em Estudos da Linguagem pela Universidade Federal do Rio Grande do Sul (Ufrgs). Professora Adjunta do Instituto de Letras da Ufrgs. E-mail: ssilvana2011@gmail.com
}

Data de submissão: fev. 2017 - Data de aceite: mar. 2017 http://dx.doi.org/10.5335/rdes.v13i1.6730 
mais abrangente do campo dos estudos enunciativos. Com essa visão, entendemos o potencial interdisciplinar da obra - e da linguística - de Benveniste, tal como assinalado por Flores (2005). No Brasil, estudos avançam na direção de uma relação interdisciplinar entre uma linguística e uma antropologia, estabelecendo outras categorias teórico-metodológicas, a saber, Silva (2013) e Silva e Malcorra (2016).

Neste trabalho, pretendemos avançar em outra direção interdisciplinar, a saber, a relação língua/indivíduo/ sociedade: "Tema um tanto polêmico é a presença de uma visão de sociedade na teoria de Benveniste" (FLORES, 2013, p. 120). O objetivo do presente artigo é realizar uma leitura da noção de sociedade em Benveniste, a partir de uma leitura transversal entre os artigos "A semiologia da língua", de Problemas de Linguística Geral I, e "Philos", do livro Estatutos sociais, Vocabulário das Instituições Indo-europeias I, de Benveniste. Dessa leitura, observamos que a noção de gesto surge como noção mediadora entre língua e sociedade. Em seguida, busca compreender o lugar da noção de gesto na teoria linguística de Benveniste. Para isso, nos valemos do artigo "Forma e sentido na linguagem" (Problemas de Linguística Geral II).

\section{Relações semiológicas entre língua e sociedade: engendramento, homologia e/ou interpretância?}

Neste item, procederemos a uma leitura que chamamos de vai e vem (SILVA, 2013), isto é, uma leitura em que critérios de um artigo de Benveniste refluem sobre um anterior, iluminando-o e trazendo novas leituras. Para este artigo, traremos uma breve abordagem do que constituiria as relações entre língua e sociedade pelo viés de uma "Teoria Semiológica da Enunciação", de Émile Benveniste. Tomamos a ousadia de assim denominar o que Flores (2013) nomeia a segunda fase do pensamento de Benveniste.

Em "Semiologia da língua", Benveniste nos informa que "o problema central da semiologia é o estatuto da língua em meio aos sistemas de signos" (1989, p. 51). O autor não deixa claro, inicialmente, a que se refere o termo "sistema de signos". Mais adiante, ao tratar das relações entre língua e sociedade, quando diz que "a língua pode, em princípio, tudo categorizar" (1989, p. 62), fica claro que a sociedade pode ser concebida também como um sistema semiótico. Dentre as relações entre sistemas semióticos (engendramento, homologia e interpretância), Benveniste situa as relações entre língua e sociedade como de interpretância. 
A relação de interpretância é explicada pela base de sistema interpretante ou articulante e sistema interpretado ou articulado, considerando que $a$ língua é o sistema interpretante dos demais. Portanto, a sociedade é o sistema interpretado e a língua o sistema interpretante, constituindo uma relação de "dependência mútua segundo sua capacidade de semiotização" (1989, p. 65). Com essa citação, entendemos que os sistemas semióticos somente podem ser compreendidos em sua relação com a língua na medida em que for possível constituir 'unidades significantes' nomeadas pela língua. Mais adiante, Benveniste explica porque a língua é o sistema interpretante da sociedade e de todos os outros sistemas semiológicos. Vejamos: "A língua é investida de uma dupla significância, o modo semiótico e o modo semântico" (1989, p. 64). O modo semiótico é a capacidade de constituir unidades pela propriedade da distintividade; o modo semântico é da ordem do discurso: o sentido (o 'intencionado') concebido globalmente que se realiza e se divide em signos (1989, p. 65). De certa forma, podemos compreender que $o$ modo semântico 'desfaz' e 'refaz' o modo semiótico, recriando novas unidades de significância (DESSONS, 2006).

\section{Benveniste acrescenta:}

[...] os outros sistemas têm uma significância unidimensional: ou semiótica (gestos de cortesia etc.) sem semântica, ou semântica (expressões artísticas) sem semiótica (1989, p. 66).
A qual dos dois casos pertence a 'sociedade'? Acreditamos que a sociedade tem caracterização semiótica; no entanto, ao se relacionar com a língua, acaba, com ela e por ela, tornando-se duplamente significante. A resposta a essa questão é dada por Benveniste em duas etapas, dada a sua complexidade:

[...] num nível fundamental, podemos perceber imediatamente a homologia. Alguns caracteres são comuns a uma e outra, à língua e à sociedade - repito eu - neste nível. [...] Tomaremos língua e sociedade em sincronia e numa relação semiológica: a relação de interpretante e interpretado. E formularemos estas duas proposições conjuntas: em primeiro lugar, a língua é interpretante da sociedade; em segundo lugar, a língua contém a sociedade (BENVENISTE, 1989, p. 96-97).

Benveniste reconhece a autonomia da 'sociedade' como sistema semiótico ao mesmo tempo que indica que essa 'autonomia' somente é possível graças à língua e sua dupla natureza de representar e de ser representada. Vejamos:

Acima das classes, acima dos grupos e das atividades particularizadas, reina um poder coesivo que faz uma comunidade de um agregado de indivíduos e que cria a própria possibilidade de produção e da subsistência coletiva. Este poder é a língua e apenas a língua. É porque a língua representa uma permanência no seio da sociedade que muda, uma constância que interliga as atividades sempre diversificadas. [...] Daí procede a dupla natureza profundamente paradoxal da língua, ao mesmo tempo imanente ao indivíduo e transcendente à sociedade. Essa dualidade se encontra em todas as propriedades da língua (BENVENISTE, 1989, p. 97). 
Benveniste faz um esclarecimento final sobre a fundação da relação semiológica:

[...] é necessário ultrapassar a noção saussuriana de signo [...] essa ultrapassagem far-se-á por duas vias: - na análise intralinguística, pela abertura de uma nova dimensão, a do discurso, que denominamos semântica; - na análise translinguística dos textos, das obras, pela elaboração de uma metassemântica que se construirá sobre a semântica da enunciação (1989, p. 67).

A primeira observação importante a se fazer sobre essa citação é que ela indica que há duas vias para a análise semiológica. Sublinhe-se: 'vias', e não 'níveis'. Esse fato não deixa de nos chamar atenção: a noção de 'nível' é bastante cara em uma análise linguística estrutural, de Martinet a Hjelmslev. Como Benveniste afasta-se paulatinamente do chamado 'estruturalismo', não é de se espantar que a palavra nível apareça somente na teorização do texto Níveis de análise linguística. Assim, compreendemos que a análise semântica do discurso propõe-se à criação de novas categorias analíticas; e a análise translinguística de textos e obras propõe-se à consideração de níveis de linguagem internos às obras, a partir de critérios enunciativos estabelecidos pela semântica do discurso.

A noção de vias linguísticas está atrelada, então, a especificidades textuais, discursivas e, também, sociais, enquanto a noção de níveis linguísticos está atrelada ao funcionamento da própria língua. Nesse sentido, a análise semiológica da língua é uma constante reinvenção da língua, uma abertura ao imprevisto do sentido.

No item a seguir, especificaremos como podemos entender as relações entre língua e sociedade como uma via linguística de análise.

\section{Uma via linguística de análise: as relações entre língua e sociedade em "Philos"}

Inicialmente, teceremos considerações sobre o artigo "Philos", do livro Os estatutos sociais, do Vocabulário das Instituições Indo-europeias. O livro Estatutos sociais tem seis capítulos: o primeiro versa sobre as funções sociais; o segundo, sobre a pertença social; o terceiro, sobre o homem livre; o quarto, sobre a amizade; o quinto, sobre o homem escravo; o sexto, sobre a formação das comunidades. "Philos" traz vários exemplos-análises de situações de amizade para explicar o sentido de uma palavra em Grego. Nesse capítulo, observamos a presença marcante da noção de 'gesto' como atrelada à noção de signo linguístico e, principalmente, à noção de sociedade/ relações sociais. Encontramos, assim, na noção de gesto uma via linguística para a compreensão das relações entre língua e sociedade.

Acreditamos, ainda, que uma leitura epistemológica da obra de Benveniste deve considerar as relações entre língua e sociedade como relações abertas, isto 
é, como relações por vias linguísticas considerando especificidades discursivas e textuais.

No artigo "Philos", Benveniste rebate uma concepção do sentido de 'philos' com a ideia de 'posse'. Inicia sua argumentação aproximando a palavra cius, "cidadão" - qualidade do cidadão e conjunto dos cidadãos -, em latim, à forma seva, em sânscrito e germânico, que significa 'amigável'. Enfatiza que essa é uma aproximação de forma, e não de sentido. Assim, como dissemos anteriormente, há uma relação estreita entre instituições: política, representada por civis, e familiar-amigável, representada por seva. Benveniste escolhe uma via linguística: a semântica da enunciação, pela aproximação do sentido de instituições semelhantes, a partir da identidade formal entre termos de línguas diferentes.

Em seguida, o autor distingue sentidos em germânico: nesse grupo de línguas, há uma ligação com instituição familiar e conjugal. Mostra que há nesse grupo uma especialização de sentidos: há uma palavra - guarda-waldans para designar "aquele que tem o poder no recinto da casa" e uma palavra para "aquele que é senhor no grupo familiar" - heiwa-frauja -, portanto, entre "casa" como habitação e domínio fechado e como círculo da família e laço matrimonial, isto é, “domínio aberto". Uma relação bastante significativa observa Benveniste em latim:
Entre a antiga relação de amizade indicada em seva, a relação mais marcada de "grupo de aliança matrimonial”, que aparece no germânico e, finalmente, o conceito de "compartilhando direitos políticos" no latim cius, há como que um progresso em três etapas, desde o grupo restrito até a cidade (1995, p. 333).

Nessa via linguística, Benveniste reconstrói sentidos e supõe uma evolução histórica a partir da abertura do signo em diferentes configurações de uma mesma instituição.

Em seguida, Benveniste passa à análise do termo 'philos', que, segundo ele, tem uma história bem mais complexa. Nesse ponto, o texto de Benveniste parece, a nosso ver, forjar outro conceito de enunciação, além do já bastante conhecido "ato individual de utilização da língua”, exposto em $O$ aparelho formal da enunciação. No presente caso, a noção de "gesto" é fundamental. Em grego, o substantivo 'philos' (amigo) está associado ao verbo 'philein', que significa 'beijar'. A seguir, ilustra o gesto do beijo com diferentes significados em algumas passagens do encontro de tribos guerreiras amigas em Homero: 1) beijar nas faces, como sinal de respeito e de posição de inferioridade de um em relação ao outro; 2) beijar na boca, como sinal de igualdade em situação de encontro; 3) prostrar-se ao chão e beijar a mão, se um deles é de nascimento muito inferior (BENVENISTE, 1995, p. 339). Nesse sentido, Benveniste observa a relação entre a instituição da amizade e a instituição das relações sociais e 
hierárquicas entre os membros de um grupo. Em síntese:

[...] o comportamento indicado por philein sempre tem o caráter obrigatório e sempre implica reciprocidade; é o cumprimento dos atos positivos suposto pelo pacto de hospitalidade mútua (1995, p. 339).

Constatamos que a noção de 'gesto de reciprocidade entre amigos' é fundadora das diversas relações de reciprocidade entre aqueles que se instituem e são instituídos de philia, de amizade. A forma do gesto e a posição em que os sujeitos se encontram e se 'gestualizam' determinam o sentido de tal reciprocidade social, seja de respeito, seja de reverência à igualdade ou à intimidade sexual entre cônjuges. Tal é a produtividade da língua grega, a única em que substantivo e verbo têm a mesma forma. Benveniste conclui:

Toda essa riqueza conceitual ficou sepultada e desapareceu das vistas desde que philos foi reduzido a uma vaga noção de amizade ou a uma falsa noção de possessivo. Já é mais do que tempo de reaprender a ler Homero (1995, p. 347).

A partir da citação acima, fica a pergunta no ar: o que da instituição social da amizade, marcada fortemente no grego antigo, e sua correlata noção de 'gesto' como 'ato enunciativo' permanece hoje nas diferentes línguas? Como perceber essa relação entre uso da língua e 'gesto social'? Que vias linguísticas podemos estabelecer entre língua e sociedade a partir das reflexões de Benveniste?

\section{Gesto como conceito linguístico da instituição social}

Em "Semiologia da língua", aprendemos que o signo, enquanto princípio semiótico da língua, deve ser 'ultrapassado' em nome da abertura da dimensão semiótica em benefício da dimensão semântica da língua. Nessa ultrapassagem, a dimensão social do uso da língua ganha relevo. Com o texto "Philos", compreendemos que, na instituição social da amizade, seja entre guerreiros, seja entre cônjuges, o gesto, isto é, a instauração das diversas formas de reciprocidade que institui, é o 'signo' de uma instituição social precisa. Com isso, acreditamos que essa noção nos permite estabelecer análises semiológicas precisas de textos, obras, compreendendo as formas de reciprocidade em diversas situações para além da epopeia homérica. Teremos, assim, outras vias linguísticas, compreendendo como o 'toque entre corpos' - seja por meio do beijo ou de outras formas -é estabelecido em diferentes culturas e sociedades. Queremos dizer, por fim, que vemos no gesto um princípio semiológico de linguística geral, o elo entre língua e sociedade. 


\section{O gesto sob perspectiva enunciativa: fato não linguístico e sublinguístico}

No texto A forma e o sentido na linguagem, Benveniste discute, dentre outras coisas, as relações de semântico e semiótico na língua, mostrando como esses conceitos se diferenciam e, ao mesmo tempo, coadunam-se; é também nesse texto que Benveniste sugere o gesto como ato enunciativo. É necessário frisar que o gesto é apenas mencionado nesse texto, ou seja, não há discussão sobre sua natureza. Notamos, entretanto, uma hesitação por parte do linguista ao fazer sua única afirmação sobre o gesto nesse texto, ou seja, ao considerá-lo como ato não linguístico:

[...] há não sei quantas maneiras possíveis, em cada situação concreta e para cada locutor ou interlocutor, de convidar alguém para sentar-se, sem falar do recurso a outro sistema de comunicação que não o linguístico, no entanto sub-linguístico, do simples gesto indicando um assento (BENVENISTE, 1989, p. 232, grifo nosso).

Verificamos, nesse trecho, que, ao mostrar as diversas maneiras possíveis de enunciar algo, Benveniste considera o gesto. No entanto, o linguista não afirma explicitamente que o gesto é também um ato enunciativo, por isso, pensamos haver, nesse ponto, uma sugestão/ aproximação do ato de fala e do gesto, ambos podendo ser considerados como atos enunciativos. Percebe-se também a hesitação do autor ao considerar a natureza do gesto como não linguística, já que em seguida afirma que o gesto indicando assento é sublinguístico. Essa noção de sublinguístico deve ser questionada e problematizada, pois, ao consultar o significado da partícula sub no dicionário on-line Priberam, deparamo-nos com o significado: "sub- (latim sub, por baixo) prefixo elemento designativo de inferioridade, substituição, aproximação". É possível ver que, segundo essa definição, considerar o gesto como sublinguístico pode significar considerá-lo como inferior, substitutivo ou próximo à língua. Cabe a nós, leitores, o trabalho interpretativo ou talvez investigativo de definir qual a denotação (ou quais as denotações) para o prefixo $s u b$ nesse texto, sem perder de vista que nossa interpretação sobre esse prefixo será nossa chave de leitura da visão de Benveniste sobre o lugar do gesto na língua.

Outro artigo em que a noção de gesto é mencionada é Da subjetividade na linguagem (Problemas de Linguística Geral I). Já nesse texto, percebemos hesitação do autor ao situar o gesto em relação à linguagem. Vejamos:

Quanto ao papel de transmissão desempenhado pela linguagem, não podemos deixar de observar, de um lado, que esse papel pode caber a meios não lingüísticos - gestos, mímica (BENVENISTE, 1989, p. 284-285, grifo nosso).

Interessa-nos investigar o status/ lugar do gesto na teoria enunciativa de Benveniste, mas, para isso, é necessário colocarmos, primeiramente, a seguinte 
questão: É possível que um aspecto não linguístico ou sublinguístico (usando as palavras de Benveniste) seja analisado através da linguística enunciativa? Nesse ponto, baseamo-nos na reflexão de Aresi sobre $O$ aparelho formal $d a$ enunciação, com o intuito de legitimar a presente reflexão:

[...] se, por um lado, ele [O Aparelho Formal da Enunciação] configura-se como um "ponto de chegada" da reflexão enunciativa, por outro, ele configura-se como um "ponto de abertura”, na medida em que é possível depreender, a partir de sua leitura, um movimento de ampliação do escopo teórico da enunciação em relação aos fatos língua, ao mesmo tempo que ele deixa, para estudo futuros, novas possibilidades de análise sob a perspectiva enunciativa (ARESI, 2012, p. 177).

Interessa-nos ressaltar, da reflexão de Aresi (2012), o caráter de "ampliação do escopo teórico da enunciação" presente em $O$ aparelho. Aresi (2012) cita inúmeros temas de pesquisas, nos mais variados campos - dentre eles a sociolinguística, a fonoaudiologia, a psicolinguística - que se utilizam da teoria enunciativa. Acreditamos, assim como Aresi, que $O$ aparelho abre espaço para diferentes análises sob a perspectiva enunciativa e, por isso, consideramos viável estudar o gesto nesse sentido.

Em sua construção teórica, Benveniste propôs pensar algumas questões relativas à natureza da língua; partindo da prerrogativa de que é possível pensar o gesto a partir de Benveniste, acreditamos ser interessante analisar o tema do gesto sob questões da mesma ordem e, obviamente, tentar respondê-las: a) o gesto é de natureza semântica, semiótica ou ambas?; b) o gesto pode ser considerado um indicador de subjetividade assim como as noções de pessoa, tempo e espaço?

Começaremos a averiguar como o gesto aparece em Benveniste a partir do texto Philos, desencadeador deste estudo. Nesse texto, em que o linguista apresenta e analisa alguns dos valores da palavra philos, o gesto é apresentado como passivel de comunicar.

\begin{abstract}
Quando os persas se encontram nos caminhos, pode-se reconhecer se os que se abordam são do mesmo nível pelo seguinte sinal: em vez de se cumprimentar com palavras, eles se beijam (philéousi) na boca. Se um dos dois é de condição levemente inferior, eles se beijam (philéousi) nas faces. Se um é de nascimento muito inferior, ele se põe de joelhos e se prosterna diante do outro (Ilíada I, 134, trad. LEGRAND apud BENVENISTE, 1995, p. 339, grifo nosso).
\end{abstract}

A partir desse trecho, percebemos que o gesto assume a função e o lugar da linguagem e que, ao problematizarmos a denominação de sublinguístico, ao menos nesse exemplo, o gesto não aparece como aproximação ou inferiorização da fala, e sim como ato passível de substituí-la. Benveniste traz uma citação da qual nos é possível depreender que o gesto tem a capacidade de estabelecer uma relação entre $e u$ e $t u$, isto é, uma relação enunciativa, e que pode, também, carregar um sentido além de "cumprimentar", uma vez que, a partir dele, é possível distinguir relações sociais (quem é superior ou inferior ao outro). 
Benveniste apresenta em seu artigo outros exemplos em que o gesto, especificamente o beijo, aparece estabelecendo relações entre os sujeitos. Um dos exemplos diz respeito ao beijo na época cristã, gesto que é colocado, nesse mesmo trecho, em contextos diferentes para mostrar como seu significado pode variar:

Será preciso lembrar, na época cristã, o "beijo" (phílema, lat. osculum), sinal de reconhecimento trocado por Cristo e seus discípulos, e depois entre os membros das primeiras comunidades? Mais recentemente, o beijo é o gesto que consagra o cavaleiro na cerimônia de receber a armadura e ainda hoje marca a acolhida do dignitário numa ordem de cavalaria durante as insígnias (BENVENISTE, 1995, p. 340).

Entendemos que, nesse trecho retirado de Benveniste, o caráter sublinguístico do gesto novamente indica substituição da fala: o gesto exerce a função de comunicar o reconhecimento, no contexto do beijo trocado entre Cristo e seus discípulos, de comunicar a consagração de um cavaleiro no contexto da cerimônia de recebimento da armadura e de comunicar a acolhida do dignitário no contexto da entrega de insígnias. $\mathrm{O}$ reconhecimento, a consagração e a acolhida poderiam ser comunicados por meio de uma enunciação falada; parece-nos que, nesses casos, enunciar usando o gesto não é, de forma alguma, inferior à enunciação falada.

Ao considerarmos, nos exemplos anteriores, o gesto como passível de substituir a língua, podemos formular a seguinte pergunta: o gesto tem a capaci- dade de substituir a enunciação falada em todos os contextos? É interessante, também, retomar uma das perguntas iniciais de nosso estudo: o gesto é de natureza semântica, semiótica ou ambas?

Trataremos agora da segunda pergunta. Em Semiologia da língua, Benveniste expõe sua opinião sobre o assunto, tratando dos gestos que chama de "gestos de cortesia"; para o linguista, esses gestos são semióticos. Consideramos, entretanto, que a discussão da natureza do gesto não deve restringir-se à análise dos gestos de cortesia. Com o intuito de pensar outras categorias de gesto e de tentar responder se os gestos não ritualizados aproximam-se mais da ordem semântica ou da semiótica, propomos partir do Quadro 1. Estruturado a partir de trechos retirados de $A$ forma e o sentido na linguagem, tem com a finalidade de traçar um paralelo entre as características que Benveniste confere à ordem do semântico e à do semiótico: na coluna da esquerda, apresentaremos características do semântico e, na da direita, as características do semiótico. 
Quadro 1 - Contraposição entre características do domínio semântico e do semiótico a partir de $A$ forma e o sentido na linguagem

\begin{tabular}{|c|c|}
\hline Semântico & Semiótico \\
\hline $\begin{array}{l}\text { "não conseguimos encontrar termos melhores para definir } \\
\text { as duas modalidades fundamentais da função linguística, } \\
\text { aquela de significar para a semiótica, aquela de comunicar } \\
\text { para a semântica" (p. 229). }\end{array}$ & $\begin{array}{l}\text { "não conseguimos encontrar termos melhores para definir } \\
\text { as duas modalidades fundamentais da função linguística, } \\
\text { aquela de significar para a semiótica, aquela de comunicar } \\
\text { para a semântica" (p. 229). }\end{array}$ \\
\hline "atividade do locutor que coloca a língua er & "a propriedade da língua" (p. 230). \\
\hline $\begin{array}{l}\text { "a frase, expressão do semântico, não é senão particular" } \\
\text { (p. 230). }\end{array}$ & $\begin{array}{l}\text { "o signo semiótico existe em si, funda a realidade da língua, } \\
\text { mas ele não encontra aplicações particulares" (p. 230). }\end{array}$ \\
\hline "com a frase liga-se às coisas fora da língua" (p. 230). & "Com o signo tem-se a realidade intrínseca da língua" (p. 230). \\
\hline $\begin{array}{l}\text { "[...] o sentido da frase implica referência a situação de } \\
\text { discurso do locutor" (p. 230). }\end{array}$ & $\begin{array}{l}\text { "[...] o signo tem por parte integrante o significado, que } \\
\text { lhe é inerente" (p. 230). }\end{array}$ \\
\hline $\begin{array}{l}\text { "[...] o sentido (na acepção semântica que acabamos de } \\
\text { caracterizar) se realiza na e por uma forma específica, } \\
\text { aquela do sintagma, diferentemente do semiótico, que } \\
\text { se define por uma relação de paradigma. De um lado, a } \\
\text { substituição, de outro a conexão, tais são as operações } \\
\text { típicas e complementares" (p. 230). }\end{array}$ & $\begin{array}{l}\text { "[...] o sentido (na acepção semântica que acabamos de } \\
\text { caracterizar) se realiza na e por uma forma específica, } \\
\text { aquela do sintagma, diferentemente do semiótico, que se } \\
\text { define por uma relação de paradigma. De um lado, a subs- } \\
\text { tituição, de outro a conexão, tais são as operações típicas } \\
\text { e complementares" (p. 230). }\end{array}$ \\
\hline Unidade semântica = palavra & Unidade semiótica $=$ signo \\
\hline $\begin{array}{l}\text { "A frase é então cada vez mais um acontecimento diferente; ela } \\
\text { não existe senão no instante em que é proferida e se apaga nes- } \\
\text { te instante; é um acontecimento que desaparece. Ela não pode, } \\
\text { sem contradição de termos, comportar emprego" (p. 231). }\end{array}$ & $\begin{array}{l}\text { "[...] ao contrário, as palavras que estão dispostas na ca- } \\
\text { deia e cujo sentido resulta precisamente da maneira em } \\
\text { que são combinadas não têm senão empregos" (p. 232). }\end{array}$ \\
\hline $\begin{array}{l}\text { "Ora, as palavras, instrumentos da expressão semântica, são } \\
\text { materialmente os signos do repertório semiótico" (p. 233). }\end{array}$ & $\begin{array}{l}\text { "Ora, as palavras, instrumentos da expressão semântica, são } \\
\text { materialmente os signos do repertório semiótico" (p. 233). }\end{array}$ \\
\hline $\begin{array}{l}\text { "Pode-se transpor o semantismo de uma língua para outra, } \\
{[\ldots] \text { mas não se pode transpor o semioticismo de uma }} \\
\text { língua para outra; [...] Atinge-se aqui a diferença entre o } \\
\text { semiótico e o semântico" (p. 233). }\end{array}$ & $\begin{array}{l}\text { "Pode-se transpor o semantismo de uma língua para outra, } \\
\text { [...] mas não se pode transpor o semioticismo de uma } \\
\text { língua para outra; [...] Atinge-se aqui a diferença entre o } \\
\text { semiótico e o semântico" (p. 233). }\end{array}$ \\
\hline $\begin{array}{l}\text { "Sobre este fundamento semiótico, a língua-discurso cons- } \\
\text { trói uma semântica própria, uma significação intencionada, } \\
\text { produzida pela sintagmatização das palavras em que cada } \\
\text { palavra não retém senão uma pequena parte do valor que } \\
\text { tem enquanto signo" (p. 233). }\end{array}$ & $\begin{array}{l}\text { "Esses dois sistemas se superpõe assim na língua tal como a utili- } \\
\text { zamos. Na base, há o sistema semiótico, organização de signos, } \\
\text { segundo o critério da significação, tendo cada um destes signos } \\
\text { uma denotação conceptual e incluindo numa sub-unidade o } \\
\text { conjunto de seus substitutos paradigmáticos" (p. 233) }\end{array}$ \\
\hline
\end{tabular}

Fonte: Elaborado pela autora.

Com base no Quadro 1, verificamos que o domínio do semiótico está ligado ao sistema de signos da língua, às formas e às suas regularidades. $\mathrm{O}$ domínio semântico está ligado à enunciação, ao irregular, único e irrepetível. Os elementos do nível semiótico são conceptuais, genéricos e não circunstanciais, enquanto o nível semântico introduz o domínio da língua em uso e em ação. 
Quando consideramos esses dois domínios para o estudo da natureza do gesto, percebemos uma divergência decorrente da categoria de gesto em questão. Na análise dos "gestos ritualizados" - segundo a denominação de Benveniste -, sua natureza parece estar mais próxima do domínio semiótico. Alguns dos gestos que utilizamos no dia a dia não têm seu sentido condicionado pelo uso e, embora sejam interpretados pela língua, o significado do gesto não muda em decorrência do contexto. Quando posicionamos o dedo indicador na frente dos lábios, por exemplo, estamos indicando ou pedindo silêncio. Esse gesto já está ritualizado em nossa cultura, de forma que não precisamos usá-lo acompanhado da fala para sermos compreendidos. Além disso, é extremamente difícil imaginar algum contexto em que esse gesto seja compreendido de outra maneira que não seja a indicação ou o pedido de silêncio.

Porém, nem todos os gestos se comportam da mesma maneira. Há tipos de gestos que utilizamos diariamente nos quais o sentido depende ou decorre do contexto e, muitas vezes, precisam ser acompanhados da fala para serem compreendidos. Nessa categoria de gesto, em que não há um significado intrínseco, ou seja, o significado do gesto depende do contexto, eles parecem estar muito mais relacionados ao domínio semântico do que ao semiótico. Assim, consideramos que há gestos ritualizados e gestos não ritualizados, ou, para usar a terminologia de Benveniste: "gestos de cortesia" e "gestos".

\section{Considerações finais}

É importante frisar que, embora consideremos que as perguntas levantadas no início da pesquisa tenham sido, de alguma forma, respondidas, não pretendemos colocar um ponto final na discussão. O gesto em Benveniste, por ser um tema de estudo novo, merece ser teorizado: a exemplo da Teoria do Ritmo, de Henri Meschonnic (1982), que fundou um novo lugar para o signo na língua $\mathrm{e}$ para o ritmo na linguagem, entendemos que a noção de gesto merece discussão, leituras, teorização. Futuros estudos podem conceber gestos que apresentem, assim como a língua, dupla significação, isto é, pertençam ao domínio semântico e ao semiótico. Nesse caso, seria necessário rever a relação entre língua e gesto e língua e sociedade, ousando propor uma análise translinguística do gesto. No entanto, acreditamos que tal argumentação terá mais consistência com a abordagem paralela das relações entre as noções de língua e linguagem em Benveniste.

Uma das questões que merece estudo é a seguinte: o gesto é um indicador de subjetividade, tal como são as categorias de pessoa, espaço e tempo? Para realizar esse propósito, acreditamos ser necessário retomar as reflexões de Silva (2013). No entanto, o presente estudo, ao constatar que o gesto é um tipo de 'signo' social, relacionando língua e sociedade, já nos traz indícios de que ele pode, sim, ser considerado como um indicador de subjetividade. 


\section{A reading of the relations} between language and society in Émile Benveniste from the notion of gesture

\begin{abstract}
The aim of this article is to accomplish a reading of the notion of society in Benveniste, based on the articulation between language / individual / society. In order to reach this purpose, we will make a transversal reading between the articles "A semiologia da língua" of Problemas de Linguística Geral I and "Philos" of the book Social Statutes of the work Vocabulário das Instituições Indo-Europeias by Émile Benveniste. One of the first observations is that the notion of gesture is the link between language and society. In view of this observation, we decided to investigate the notion of gesture in Benveniste more closely. From the study of the text "A forma e o sentido na linguagem", by Benveniste, it was possible to begin to understand the place of the gesture in the language and its relation with the pair language / discourse.
\end{abstract}

Keywords: Society. Gesture in enonciative perspective. Émile Benveniste.

\section{Referências}

ARESI, Fabio. Síntese, organização e abertura do pensamento enunciativo de Émile Benveniste. 2012. 207 f. Dissertação (Mestrado em Teorias do Texto e do Discurso) - Programa de Pós-Graduação em Letras, Universidade Federal do Rio Grande do Sul, Porto Alegre, 2012.
BENVENISTE, Émile. Semiologia da língua.

In: . Problemas de lingüística geral II.

Campinas, SP: Pontes, 1989. p. 43-67.

Estrutura da língua e estrutura

da sociedade. In: Problemas de lingüística geral II. Campinas, SP: Pontes, 1989. p. 91-104.

. A forma e o sentido na linguagem. In: _. Problemas de lingüística Geral II. Campinas, SP: Pontes, 1989. p. 220-242. Philos. In: O Vocabulário das Instituições Indo-europeias. Vol I. Economia, Parentesco, Sociedade. Campinas, SP: Pontes, 1995. p. 331-348.

DESSONS, Gerard. Émile Benveniste: l'invention du discours. Paris: Limoges, 2006. p. 93-95.

FLORES, Valdir. Por que gosto de Benveniste? Desenredo, Passo Fundo, v. 1, n. 2, p. 127-138, 2005. Disponível em: <http://seer. fclar.unesp.br/casa/article/view/575/495>. Acesso em: 10 mar. 2012.

FLORES, Valdir. Introdução à teoria enunciativa de Benveniste. São Paulo: Parábola, 2013. FLORES, Valdir et al. Dicionário de Linguística da Enunciação. São Paulo: Contexto, 2009. MESCHONNIC, Henri. Critique du rythme. Paris: Verdier, 1982.

ONO, Aya. La notion d'énonciation chez Benveniste. Paris: Limoges, 2007.

SILVA, Silvana. O homem na língua: uma visão antropológica da enunciação para o ensino de escrita. Tese (Doutoramento em Estudos da Linguagem) - Universidade Federal do Rio Grande do Sul, Porto Alegre. 2013.

SILVA, Silvana; MALCORRA, Bárbara. Sociedade, sociedades: epistemologia para princípios da teoria social da enunciação. (Con) textos Linguísticos, Vitória, v. 10, n. 17, 2016. Disponível em: <http://www.periodicos.ufes. br/contextoslinguisticos/article/view/14802>. Acesso em: 9 jan. 2017. 